\title{
EL MUSEU DE MALLORCA APUESTA POR EL ARTE Y LA GASTRONOMÍA
}

\author{
Maria Gràcia Salvà Picó ${ }^{a}$, Pablo José Acover Cateura ${ }^{b}$ \\ a Directora Museu de Mallorca. Secció Etnològica de Muro. Museu Monogràfic de Pollentia. \\ mdm.mgsalva@conselldemallorca.net \\ b Profesor asociado a la Universidad de Alicante. Departamento de Historia Medieval, Moderna. Cien- \\ cias y Técnicas Historiográficas. pablo.alcover@ua.es
}

\begin{abstract}
Art from the palate and the word. The Museum of Mallorca, has started a line of research and dissemination of analysis of works of art in its permanent collection through gastronomy. To this end, three series of lectures-workshops have been organized, with great public success, on medieval food, on wine and on chocolate. The objective of the communication is to publicize these activities, as well as to present the new line of museum research around the study of art through a taste for gastronomy.
\end{abstract}

Keywords: museums, gastronomy, medieval food, mancerinas and jícaras, wine, chocolate, Mallorca.

Resumen: Arte desde el paladary la palabra. El Museu de Mallorca, ha iniciado una línea de investigación y de difusión de análisis de obras de arte de su colección permanente a través de la gastronomía. A tal efecto se han organizado tres ciclos de conferencias-taller, con gran éxito de público, sobre alimentación medieval, sobre el vino y sobre el chocolate, El objetivo de la comunicación es dar a conocer estas actividades, así como presentar la nueva línea de investigación del museo entorno al estudio del arte a través del gusto por la gastronomía.

Palabras clave: museos, gastronomía, alimentación medieval, mancerinas y jícaras, vino, chocolate, Mallorca.

Citar como: Maria Gràcia Salvà Picó, M.G., Acover Cateura, P. J. (2022). "El Museu de Mallorca apuesta por el arte y la gastronomía". En: Actas del III Congreso Internacional sobre Patrimonio Alimentario y Museos. 25-26 noviembre, 2021, Valencia, España. pp. 157-170. https://doi.org/10.4995/EGEM2021.2021.13855 


\section{Introducción}

El Museu de Mallorca, es un equipamiento público situado en pleno centro histórico de Palma de Mallorca. Se encuentra ubicado en la calle de la Portella, antigua vía de comunicación romana, posiblemente marítima, que conduce desde la plaza de Santa Eulalia hasta el mar. Su sede es un antiguo palacio, hecho construir por Luís Ballester de Togores Salas, primer conde de Aiamans, en 1635. El casón fue remozado en el siglo XIX, en estilo neogótico, por la marquesa Catalina de Zaforteza y de Togores. La apariencia actual corresponde a esta última intervención, aunque conserva la planta pentagonal barroca, perceptible en el patio, y fragmentos arquitectónicos góticos. En el subsuelo se conservan estructuras pertenecientes a la época andalusí. Es pues un testimonio de la evolución histórica y edilicia de Mallorca desde el siglo XIII hasta el siglo XXI. Pasó a propiedad pública en el año 1968, cuando la familia Zaforteza, última propietaria, lo vendió al Ayuntamiento de Palma, quién a su vez lo cedió al Estado en 1971.

El día 2 de noviembre de 1961, este año se cumple su sesenta aniversario, se decretó la creación del Museo de Mallorca, con el objetivo inicial de preservar las especiales características y singularidades del arte mallorquín en sus diferentes manifestaciones, y con el fin de ofrecer a los investigadores y a los turistas, todos aquellos objetos de interés artístico, arqueológico o etnológico que fuesen una muestra del arte, la cultura y la manera de vivir del pueblo mallorquín a lo largo de los siglos. Su sede inicial fue la Casa de Cultura de Palma, que actualmente ocupa el Arxiu del Regne de Mallorca, y desde 1976 se trasladó a la casona de la calle Portella, número 5 de Palma, también conocida como la Gran Cristiana.

Para la exposición permanente se contó con las colecciones del antiguo Museo Provincial de Bellas Artes de la Lonja, creado en 1915 y primer museo público de la isla, diversas colecciones arqueológicas propiedad del Estado; y especialmente los bienes atesorados por la Sociedad Arqueológica Luliana, fundada en 1888, cedidos en depósito al nuevo museo. Así mismo se contó con donativos o depósitos que entidades públicas, particulares o el propio Estado efectuaron
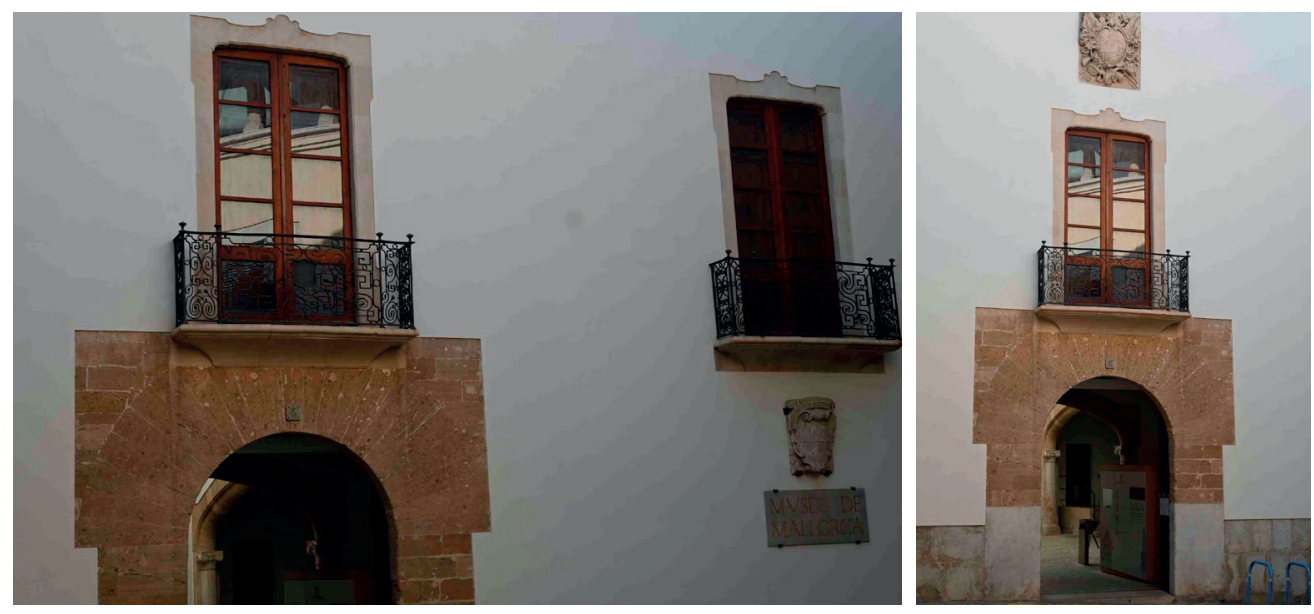

Figura 1. Entrada principal del Museu de Mallorca, en Palma. Corresponde a la reforma efectuada en el siglo XIX. Fuente: Elaboración propia. 
en su momento. Se trata pues de un museo general de Historia y Bellas Artes representativo de la cultura mallorquina, con obras que van desde la Prehistoria hasta los primeros movimientos modernos del siglo XX.

La titularidad del museo es estatal, adscrito al actual Ministerio de Cultura y Deporte, aunque su gestión fue transferida al Gobierno de las Islas Baleares en 1984, y desde el año 2019 es gestionado por el Consell Insular de Mallorca. Lo conforman tres sedes, la principal en Palma y dos secciones, la Etnológica en Muro, y el Museo monográfico de Pollentia, sito en Alcudia, en el que se muestran los materiales arqueológicos procedentes de la ciudad romana de Pollentia. Depende del museo, el área de reserva de Son Tous, almacén dónde se depositan, catalogan y guardan los objetos procedentes de las excavaciones arqueológicas de la isla.

En una primera etapa, iniciada en 1976 y finalizada en 2002, se abrieron cinco salas para exponer el arte gótico, situadas en el entresuelo y en la planta noble. Contenían piezas de arquitectura, de pintura de los siglos XIII y XV, de escultura y de cerámica de los siglos XIII al XVI. Éstas fueron las primeras estancias que se abrieron al público.

Paulatinamente se fueron inaugurando las salas del arte de los siglos XVI al XX, todas ellas situadas en las plantas noble y superior. Se expuso el arte del Renacimiento y del Barroco, en 1979; el arte de la época islámica, en 1981; el arte del siglo XIX, en 1983; el Modernismo y el siglo XX, en 1985; las artes industriales de los siglos XIII al XVIII, en 1989; y finalmente, el arte del siglo XVIII, en 1990.

El 20 de diciembre del 2000, se inauguraron trece salas dedicadas a la Prehistoria. Las diferentes dependencias estaban situadas en los sótanos y en el subsuelo del antiguo jardín, espacio recuperado tras la excavación llevada a cabo en 1998, en la que se descubrieron los restos de una casa islámica, sobre la que se habían construido los dos edificios góticos, germen del primer palacio renacentista.

El programa museográfico se dio por concluido con la apertura de ocho nuevas salas situadas en la planta baja y el sótano, inauguradas el 25 de marzo del 2002, dedicadas al talayótico final, a las colonizaciones, a la romanización y a la época tardo antigua.

La apariencia actual del museo es consecuencia de la remodelación iniciada en 2009, costeada por el entonces Ministerio de Educación, Cultura y Deportes. En aquel entonces se efectuó una rehabilitación integral del edificio, dotándolo de nuevas instalaciones y de mejoras en la accesibilidad arquitectónica. El 23 de julio de 2015, se abrieron los espacios dedicados a mostrar las colecciones de Bellas Artes y las Artes Decorativas desde el siglo XIII hasta comienzos del siglo XX, distribuidos en dos de las plantas del museo. En el tercer piso, se destinaron dos salas para acoger las exposiciones temporales. El nuevo programa obligó el cierre de las salas destinadas a la exposición de los importantes fondos arqueológicos que custodia el museo. ${ }^{1}$

Desde 2019, con la nueva dirección, se han efectuado algunos cambios. La exposición permanente de la tercera planta se ha remodelado casi completamente, a raíz de una cesión importante de obra pictórica propiedad de CaixaBank, procedente de la Fundación Sa Nostra Caixa de Baleares, entidad creada en Baleares en 1882. A corto plazo, se reabrirán las salas dedicadas a mostrar la arqueología balear y la musealización del yacimiento arqueológico situado en el subsuelo, correspondiente a una edificación andalusí.

$\overline{1}$ Guia del Museu de Mallorca. Sales de Belles Arts i Decoratives. Segles XIII al XX. Palma, 2015. 
Paralelamente a las grandes intervenciones, hemos iniciado un nuevo programa de actividades con el fin de incentivar la visita del público local que por diversos motivos, desconocía la existencia del principal museo de la isla o simplemente hacía tiempo que no lo frecuentaba. Según nuestra opinión, los museos tienen que ser espacios polifónicos, de diálogo y escenario de temas que interesen a la sociedad. Estos tres supuestos nos llevaron a organizar unos ciclos de conferencias combinados con talleres de degustación, en los que se proponía una nueva lectura de la colección de obras de arte desde un punto de vista alimentario y gastronómico. Generalmente el sentido de la vista es el que prima cuando se visita un museo, el resto de sentidos parecen o son incluso prohibidos, ¿por qué no dejarlos entrar y ampliar la percepción del arte a través del gusto?

Empezamos el ciclo con la alimentación medieval, continuamos con el vino y acabamos con el chocolate, una manera dulce de detener estas actividades debido a la irrupción de la pandemia provocada por el COVID19, que nos obligó a cerrar el museo hasta el mes de mayo de 2020. Durante este año no hemos podido reactivar estas conferencias-taller, pues las limitaciones siguen siendo muchas pero tenemos más ideas para desarrollar en los años venideros. A continuación iremos desgranando los ciclos y la evaluación de sus resultados.

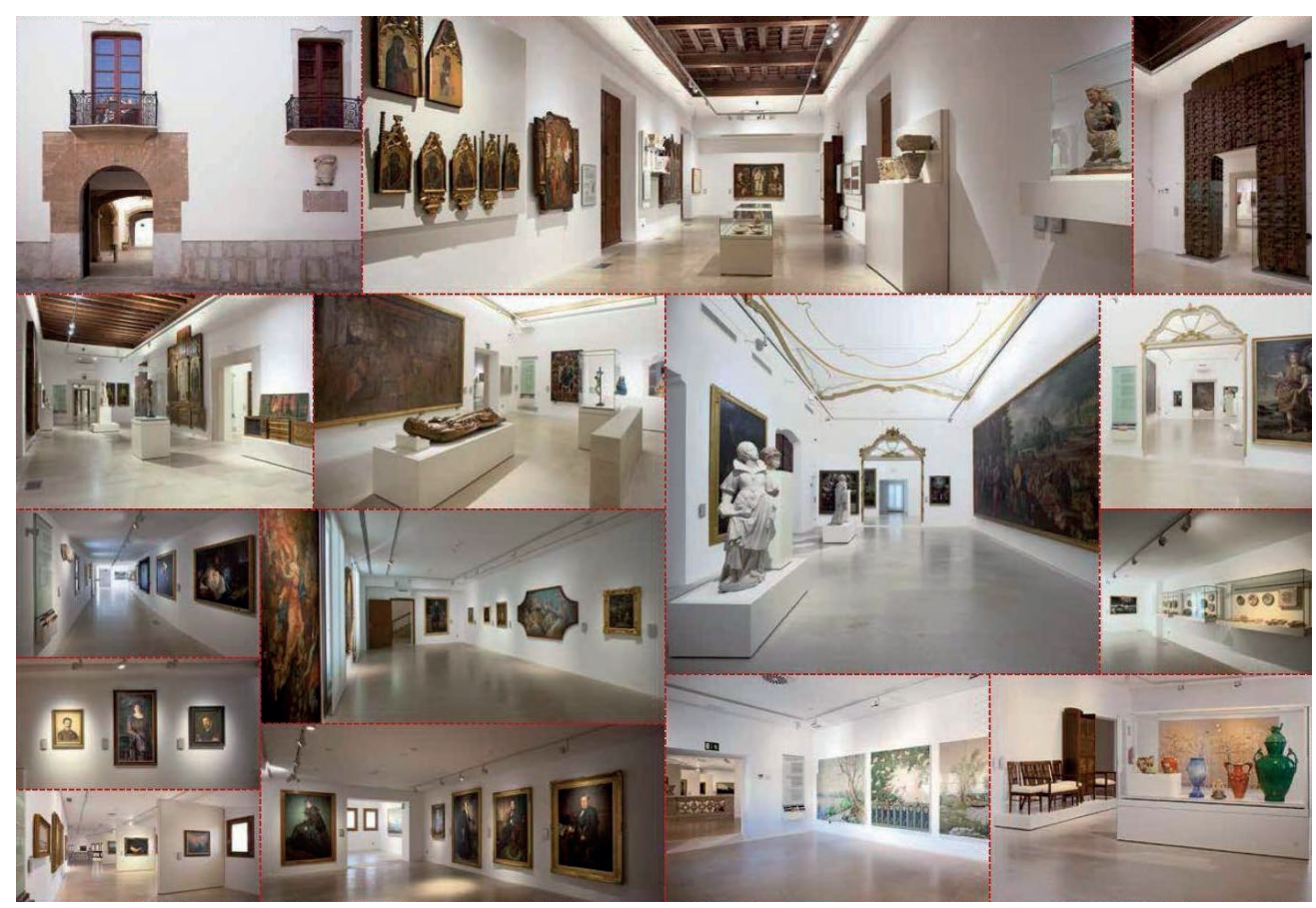

Figura 2. Interior del museo rehabilitado en 2015. El discurso museográfico se inicia en el siglo XIII, salas de la planta noble y continúa en el tercer piso con el siglo XIX.

Fuente: Elaboración propia. 


\section{Objetivos}

La sociedad actual demuestra, cada vez más, un interés por todo lo relacionado con la alimentación. Esta inclinación se refiere tanto a la nutrición, como a la tecnología de la elaboración de los alimentos, relacionadas con dos preocupaciones esenciales de la población, la salud y la economía. Los avances en la investigación sobre alimentación son muchos y variados. Casi todos conocemos qué es el aceite Omega 3 y en qué alimentos se encuentra, calculamos los hidratos de carbono, controlamos las grasas saturadas, tomamos vitaminas y nos informamos de los efectos beneficiosos o perniciosos para nuestra salud de los productos. Consecuentemente, hoy la ciencia puede recomendarnos con precisión qué comer y qué no. Sin embargo, aunque el conocimiento sobre alimentación nunca ha estado tan avanzado, hoy la obesidad es un problema global. Desde los años 80 del siglo XX, han aumentado considerablemente los malos hábitos alimentarios, con la consecuente aparición de diversas enfermedades, convirtiéndose en uno de los principales puntos de atención de la salud pública mundial. Para la Organización Mundial de la Salud (OMS), uno de los desafíos de Occidente será luchar contra la obesidad, infantil y adulta, debido al aumento paulatino e imparable de una dieta poco saludable y por el sedentarismo. En suma, la alimentación y la gastronomía son hoy temas de gran actualidad, que interesan al público y que se pueden interpretar desde una perspectiva artística. Santos, santas, reyes, reinas, duques, duquesas, obispos y la población anónima representada en retablos, cuadros, todos y todas, comían y bebían.

La alimentación es transversal y permite analizar extensos periodos de la Historia. Mediante la comida, los sistemas de producción y los tipos de consumo, se puede abarcar la historia de todas las civilizaciones que han dejado su huella en Mallorca. Economía, sociedad, arte, política, cultura, son elementos de una civilización que tienen una relación directa e incluso privilegiada con la alimentación. No podía ser de otra manera al ser la comida y la bebida imprescindibles para la supervivencia. Comer y beber tienen también el lado hedonista, condicionado por el gusto exquisito de las clases altas y por el sentido de exotismo y exclusividad que se manifiesta a través de este placer mundano.

La transversalidad y pluridisciplinariedad con el que se puede trabajar la alimentación, nos ha permitido organizar unos ciclos de conferencias y degustaciones entorno a la exposición permanente del Museo. La difusión de la colección permanente a través de la observación desde una perspectiva alimentaria ha sido su objetivo primordial.

\section{Desarrollo de la innovación}

Desde el año 2019 hasta el advenimiento de la pandemia, se organizaron tres ciclos de conferencias y talleres de degustación. Se trataron temas, elegidos en función del diálogo con la colección permanente del museo y las preferencias del público. Para el primero, celebrado en octubre de 2019, bajo el título La alimentación medieval a través de los tesoros del Museo de Mallorca, se escogió la alimentación de los siglos XIII-XV, impartido por un especialista en esta materia y época, el Dr. Pablo José Alcover Cateura.

La dieta bajo medieval mallorquina se basaba en dos alimentos esenciales, el pan y vino, junto con ellos, las carnes y pescados, cuyo consumo dependía de la época del año y la clase social, cuanto más humilde se comía más pescado y menos carne. Las verduras y frutas estaban presentes en el menú diario de los más pobres, y rara vez eran consumidas por las clases altas, al vincularse a comida de campesinos. Los embutidos obtenidos en las matanzas y los quesos obtenidos de la leche de vacas, cabras y ovejas, les permitían nutrirse todo el año. 


\section{CONFERÈNCIES SOBRE}

\section{L'ALIMENTACIÓ MEDIEVAL A TRAVÉS DELS TRESORS DEL MUSEU DE MALLORCA}

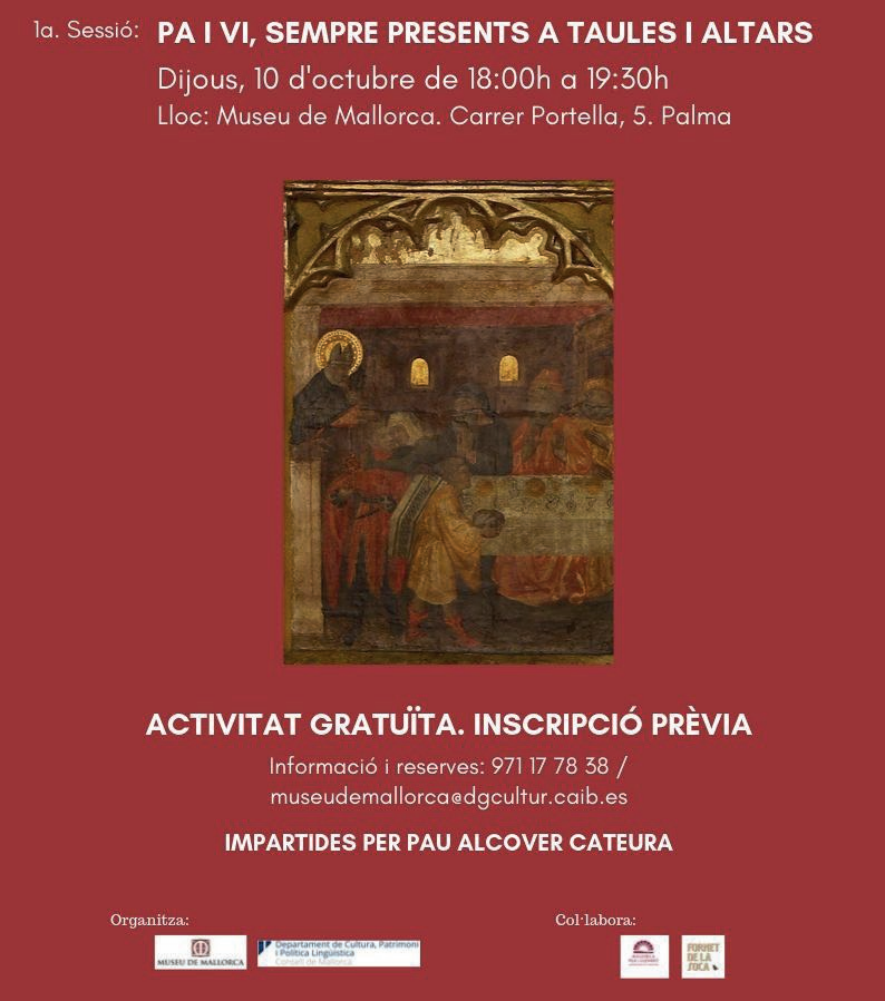

Figura 3. Primer ciclo de conferencias en los que se establece una relación entre arte y gastronomía. Fuente: Museu de Mallorca.

Pa i vi, sempre presents a taules i altars, sirvió para conocer los tipos de panes que se consumían. Cada persona tomaba, de término medio, entre ochocientos gramos y un kilo diarios. En el Retaule de sant Nicolau, sant Antoni i santa Clara, de finales del siglo XIV, una de las joyas del gótico balear, conservada en el museo, hay representada una escena inspirada en una cena de una familia aristocrática mallorquina. En ella se aprecian panes redondos y blancos, elaborados con cereales candeales, propios de los ricos, cristianos y judíos. Además, también se pueden ver panes blancos alargados, el primer testimonio gráfico del llonguet, el pan candeal que continua siendo el más típico de la ciudad de Palma. En la mesa del retablo hay pintadas copas de vidrio para el vino. El vidrio era el material más caro para la elaboración de estas piezas cotidianas, que debido a su transparencia ayudaba a prevenir el envenenamiento de los comensales. Resulta muy interesante el uso de jarras de vino y agua, ya que conservamos objetos similares de la misma época. 

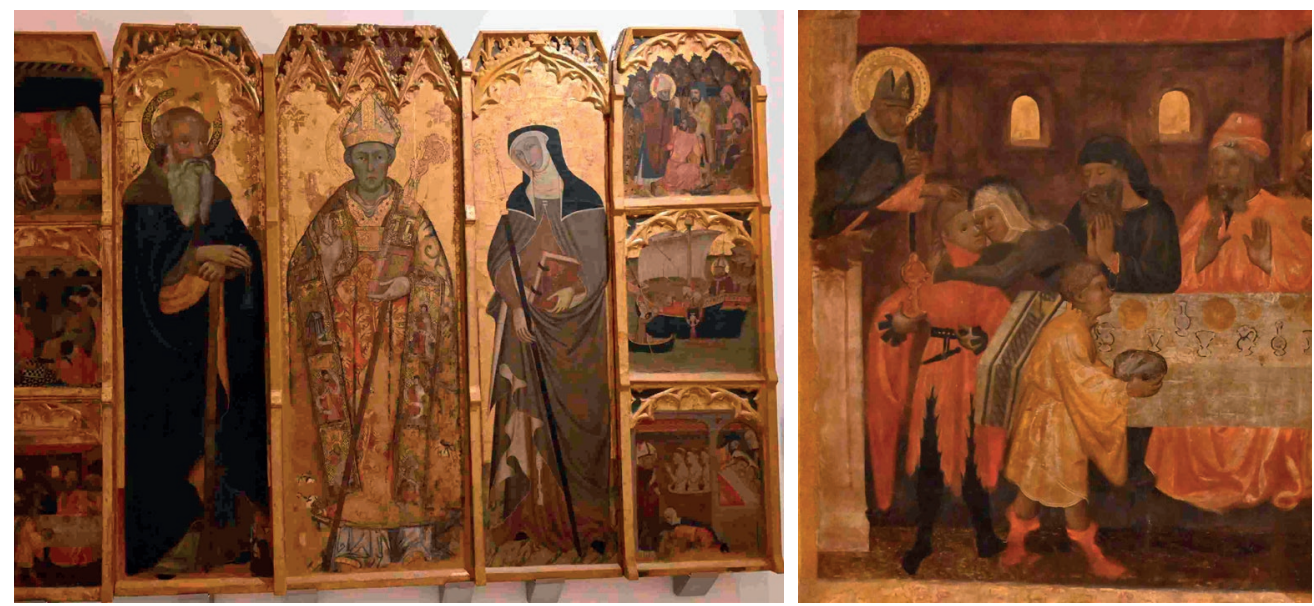

Figura 4. Retablo de San Nicolás, san Antonio y santa Clara, atribuido a Pere Marçol, Maestro de Santa Eulalia y Maestro de Santa Margarita, finales del s.xv. Detalle del compartimento inferior izquierdo, en el que se aprecian panes, jarras y otros utensilios, encima de una mesa, similar a las que había en las clases nobles. Fuente: Museu de Mallorca.

Asimismo, se procedió a una lectura con respecto al papel de las mujeres por lo que se refiere a la elaboración y venta de pan. Se sabe que a pesar de ser ellas las que se encargaban de amasar, junto con los esclavos, no tenían el mismo respeto que los hombres panaderos, que lo horneaban, proceso mejor visto que el anterior. El vino, líquido sagrado y profano, era consumido exclusivamente por hombres, en tabernas y hostales. A las mujeres, les estaba prohibido fuera de la mesa del hogar, ya que tenían a su cuidado a los hijos. Además de ir desgranando los conceptos generales, en torno al líquido elemento, se fueron introduciendo anécdotas. Por ejemplo los verdugos, podían beber públicamente pero tenían que traer la copa de su hogar, ya que se decía que la sangre de los condenados era fuente de enfermedades.

La segunda conferencia, Carns i peixos, plaers terrenals, sirvió para analizar el papel que tuvo el consumo de carne y pescado en el calendario bajo medieval, el cual se dividía entre los días carnales y los no carnales, en los que exclusivamente se comía pescado. Se describieron las carnicerías y pescaderías, los alimentos autorizados, así como los preceptos sobre la cocción de los alimentos, auspiciados por las diferentes confesiones religiosas. Los judíos debían obedecer la kashrut, la cual les prohibía consumir animales terrestres con pezuñas hendidas o rumiantes, tales como vacas, ovejas, cabras o ciervos y los pescados sin escamas, aletas dorsales y laterales. En contraposición, los cristianos no tenían restricciones alimentarias. La presencia de ciervos, gamos o jabalíes, fauna local en aquellos momentos y hoy extinguida en la isla, estaba presente en las mesas y recetario de las clases señoriales. Así como también platos cocinados con orcas, focas, delfines, salmones o atunes. En el Llibre del Coc, recetario del siglo XV, se describen recetas de abstinencia a base de salmón, tales como salmón en pan o salmón en cazuela, mientras que en el Llibre de Sent Soví, fechado en el siglo XIV, hay recetas de fritos de delfín o una salsa para atún. Por último, en el Llibre d'aparellar de menjar, del siglo XIV, se recogen recetas de salsa para jabalí, ciervo y gamo, entre otras. 
En la última conferencia, Formatge i embotits, aliments per a sobreviure a la fam, se enumeraron los alimentos elaborados para sobrevivir a los duros inviernos, época en la que el huerto casi no producía frutas y verduras. Los quesos curados de cabra, oveja roja mallorquina o de oveja y cabra, parmesano, caciocavallo, queso de Tronchón y los embutidos, tales como el bacón, la sobrasada, la longaniza o la butifarra, estaban presentes en las mesas, tanto los productos de elaboración local como los de importación. Los quesos los podía comercializar directamente cualquier vecino que los produjera o los importara y se vendían en las queserías, mientras que los embutidos se ofrecían en las carnicerías públicas, con el precio de venta regulado por las autoridades locales. La sobrasada, de origen italiano y que todavía hoy se consume en el sur de Italia, se ha convertido en uno de los productos icónicos de la isla, junto con la todavía más famosa ensaimada. En los inventarios de los almacenes de las casas populares y nobles del siglo XV, se citan las sobrasadas, elaboradas para el consumo cotidiano o para regalar a las amistades. Su consumo más habitual era como el de hoy, untada sobre pan.

El segundo ciclo, El vi de la nostra terra. Història i actualitat d'un producte mediterrani, estuvo motivado por el hecho que el museo conserva entre sus fondos, obras relacionadas con la producción y consumo del vino. El líquido elemento, que forma parte de nuestra cultura, nos sirvió de hilo conductor para estudiarlo de una forma pluridisciplinar, desde la enología, la etnografía o la sociología. Los estudios biológicos, agrícolas y vitivinícolas, nos permiten saber todo lo relacionado con la cepa de la cual se extrae la uva, hasta el proceso de elaboración del elixir. Entre otros objetos, el museo tiene un amplio repertorio de vasos fabricados expresamente para

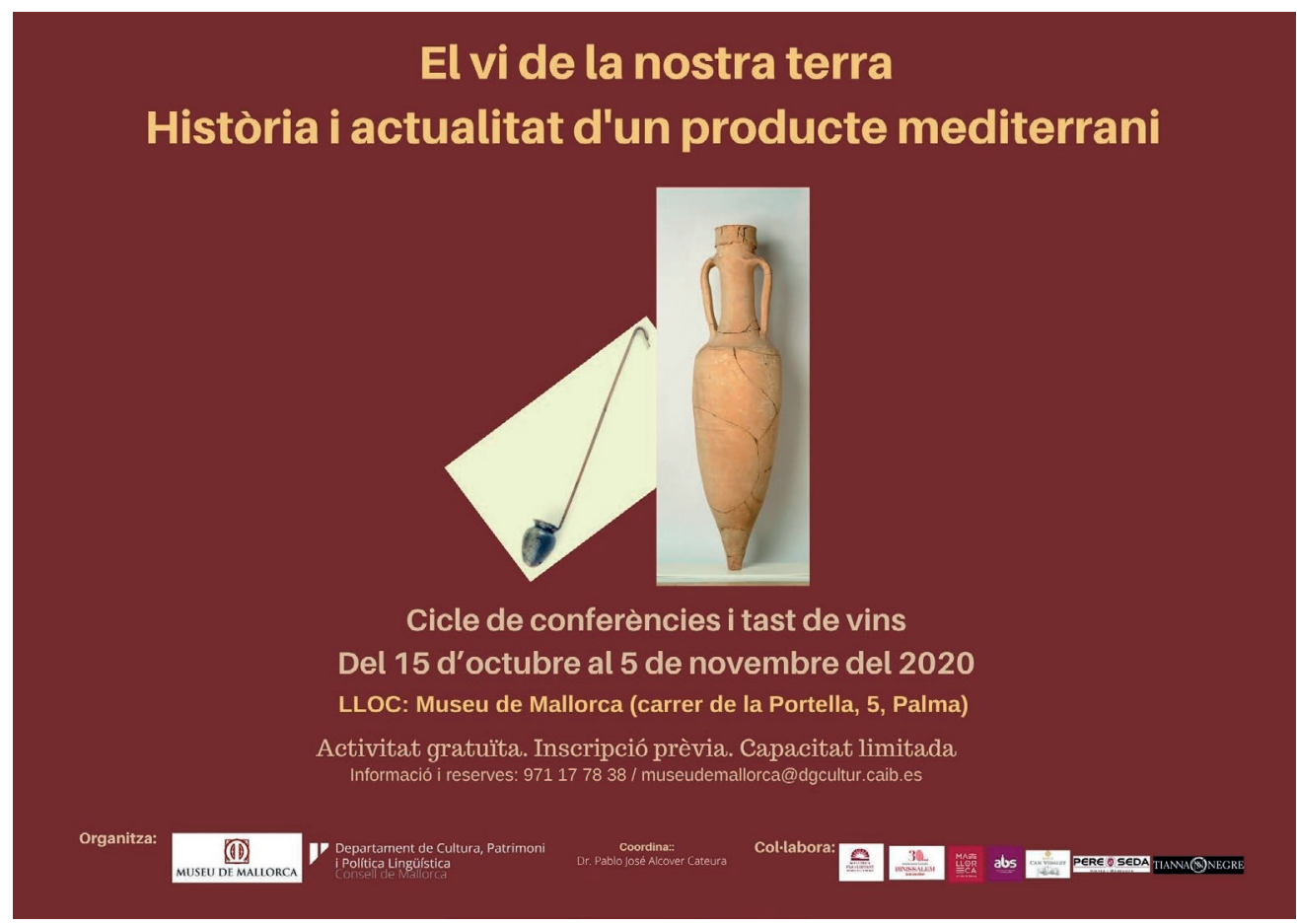

Figura 5. Cartel informativo del segundo ciclo de Arte y gastronomía, dedicado al vino. Fuente: Museu de Mallorca. 
contener o beber vino, desde la época griega, e incluso anteriores. Ánforas vinarias, cálices, jarras, copas de vidrio y otros objetos fueron diseñados expresamente para contener, saborear o hacer libaciones con el vino. A partir de la época medieval y hasta la Edad Moderna, se usaron escudillas o vasos de cerámica, para las clases populares y copas de cristal, opción preferida por las clases alta y eclesiástica. En retablos y cuadros, aparecen en múltiples ocasiones, mesas puestas con alimentos y contenedores de alimentos. Ver estas obras desde la perspectiva vinaria es una manera de ofrecer nuevas formas de interpretación de las obras de arte.

En Vi: beguda divina y humana. Dels inicis llegendaris al seu consum diari a la Mallorca del segle XVIII, impartida por el Dr. Miguel Garí, se enmarcó en una lectura histórica del vino desde sus remotos orígenes hasta el siglo XVIII. De Hipócrates a Arnau de Vilanova, se resaltaron los efectos beneficios de sus efluvios y consumo, por su alto poder nutriente, como transportador de las encimas de los alimentos, como digestivo y de utilidad para mejorar el sistema nervioso.

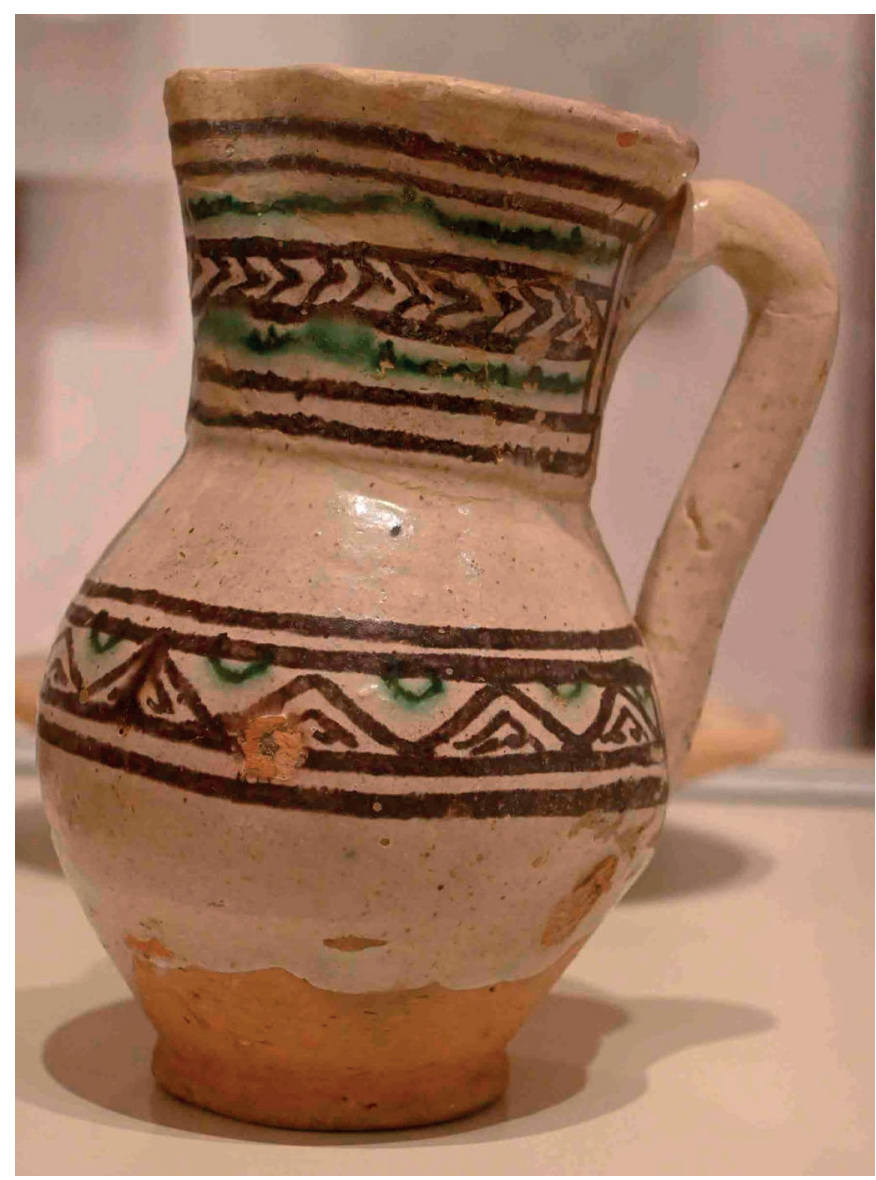

Figura 6. CJarra de loza de verde y manganeso fechada en el siglo XIV. Posiblemente fue usada para contener vino y/o agua.

Fuente: Museu de Mallorca. 
La segunda conferencia El consum de vi a Mallorca i a la Mediterrània. Una visió des de l'antropologia, presentada por la Dra. Margalida Mulet, fue temática y cronológicamente una continuación de la anterior. Como muestra gráfica se aportó las fotografías antiguas que posee el museo, relacionadas con el tema. Desde mediados del siglo XX, se pasó progresivamente de consumir uno a dos litros de vino diarios por persona adulta, a consumir una media de un vaso semanal de vino. Este menor consumo, redundó en una mejora en la producción de los caldos, anteriormente fabricados de manera doméstica, sin grandes aspiraciones relacionadas con la calidad del producto.

El Dr. José Mariano Escalona, profesor de la UIB y miembro del programa de recuperación de cepas isleñas antiguas, presentó las investigaciones efectuadas en este campo, las cuales han dado como resultado la identificación, recuperación y siembra de cepas antiguas que habían quedado en desuso. En su charla, Mallorca, terra de bon vi. Les varietats de vinya autòctones de l'illa, explicó el funcionamiento biológico de la viña. Así mismo se destacó la época de esplendor de la producción vinícola de la isla en el siglo XIX a causa de la filoxera que arrasó las vides francesas. Desde hace unos años, ha habido un segundo auge vinario debido a la recuperación de la producción, destacando los vinos elaborados con las variantes locales de callet y manto negro, la proliferación de bodegas y la demanda del mercado centroeuropeo.

La última conferencia Un ofici amb glamur. Conèixer l'art del sommelier a Mallorca, cerró el ciclo y fue expuesto por Daniel Arias, actual presidente de la Asociación de Sommeliers de Baleares. Su objetivo principal fue explicar el oficio de somelier, lo cual fue de mucha utilidad para poner en práctica lo aprendido en la cata de vinos que se efectuó en el patio del museo, ofrecida por las bodegas agrupadas bajo las denominaciones DO Mallorca, Pla i Llevant y DO Binissalem.

A raíz de la cesión al museo de un conjunto de objetos de cerámica de la colección Marroig, propiedad del Consell de Mallorca, se nos ocurrió iniciar una nueva línea de investigación en torno a la nueva colección del museo y el consumo de chocolate. Bartomeu Marroig Mesquida, coleccionó entre otros objetos, jícaras y mancerinas de Alcora y de otros talleres, objetos diseñados ex profeso para la bebida de los dioses, fechados desde finales del siglo XVIII a principios del XIX. Las cerámicas se expusieron y con la intención de dar a conocer al público dichos objetos y dado el éxito de los dos ciclos anteriores, organizamos una serie de conferencias y talleres de degustación relacionados con la historia del chocolate y su consumo en Mallorca. Esta fue la última actividad que se pudo efectuar presencialmente debido a la irrupción del COVID19. La intención fue ofrecer una visión transversal y pluridisciplinar del uso del chocolate, desde una perspectiva histórica, a los métodos de fabricación, sus valores nutricionales y médicos hasta el anecdotario, la tradición, la desmitificación o mitificación del producto. El ciclo constó de dos conferencias, una cata y una ruta del chocolate. El paseo se inició en el museo y continuó por las principales confiterías y chocolaterías, hoy en día casi inexistentes, por el centro histórico de Palma. Es también una forma de preservar la memoria histórica culinaria y gustativa.

En El regal americà. Dels orígens de la xocolata a la seva consolidació com aliment quotidià a Mallorca al segle XVIII, impartida por la Dra. María de los Ángeles Pérez Samper, se enumeraron sus orígenes legendarios en América hasta su llegada a Mallorca en el siglo XVIII. Exclusivo entre las clases adineradas, en un primer momento y paulatinamente consumido por las clases sociales económicamente menos solventes. Se remarcó su vinculación con el pecado de la gula, uno de los siete capitales, y los recelos que su consumo provocó en algunos sectores conservadores de la Iglesia. 


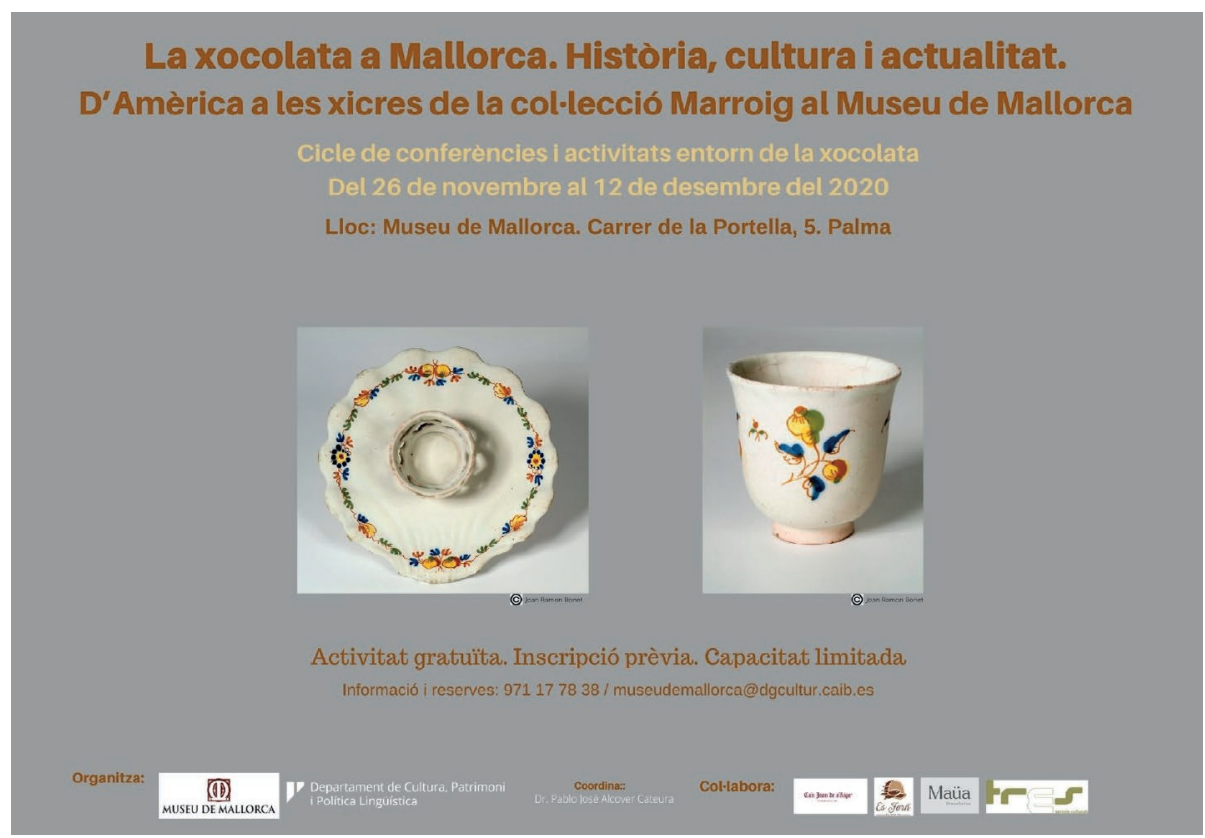

Figura 7. Tercer ciclo de Arte y gastronomía, dedicado a la relación entre la colección del museo y el chocolate.

Fuente: Museu de Mallorca.

Por otra parte, Catalina Torres presentó una conferencia titulada Les xicres de la col/lecció Marroig, ceràmiques per a la xocolata, en la que analizó el consumo de chocolate en los siglos XVIII y XIX a partir obras de arte, además de explicar los protocolos de su consumo.
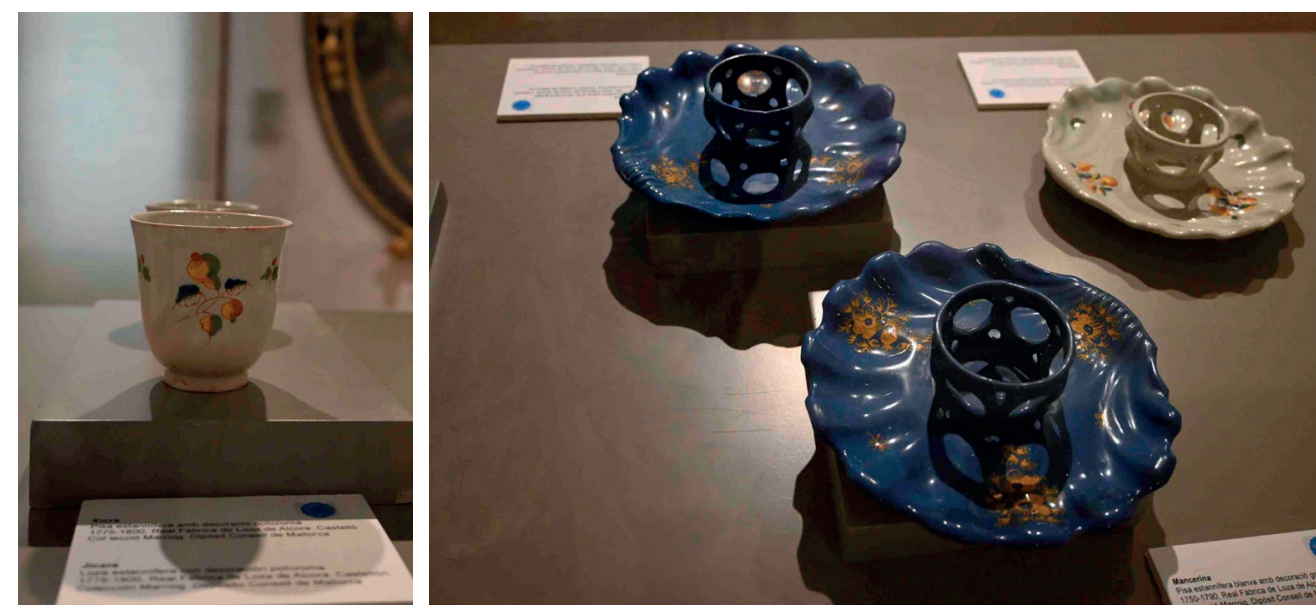

Figura 8. EJícaras de la serie Ramillete, fechadas en 1775-1780 y mancerinas azules fechadas entre 1775-1790, manufacturadas en la Real Fábrica de Loza de Alcora (Castellón). Colección Marroig. Fuente: Museu de Mallorca. 
Las otras dos actividades giraron en torno a la degustación de chocolate. Tastem la xocolata. Taller teoricopràctic, dinamizada por el Dr. Josep Tur, consistió en una cata de chocolates a partir del reconocimiento de texturas, colores, sabores, intensidad y olores. Finalmente, el paseo gastronómico por algunas de las más antiguas chocolaterías de Palma de Mallorca, quizás de las más antiguas de Europa, y la degustación de los chocolates calientes, blancos, negros, con o sin leche, hizo las delicias de los asistentes.

\section{Resultados y conclusiones}

El principal resultado de relacionar la colección del museo con la gastronomía fue el aumento del interés del público local por conocer o revisitar el museo. Las actividades efectuadas contribuyeron a aumentar las cifras de visitantes los años 2019 y 2020. ${ }^{2}$ Este hecho fue recogido por la prensa local, que señaló al Museo de Mallorca como uno de los más visitados por locales y extranjeros. ${ }^{3}$ Por lo que también tuvo un efecto mediático. Además hay que destacar el acierto de difundir la exposición permanente a través de la alimentación y la reivindicación del conocimiento y consumo de los productos locales en un momento de crisis de la agricultura isleña. ${ }^{4}$ Por otra parte, hemos iniciado nuevas lecturas de la colección. Lo comenzamos con la relectura de las piezas a través de la indumentaria de alta costura ${ }^{5}$ y ahora lo hacemos mediante la gastronomía y la difusión de las tradiciones culinarias. Como comentábamos antes nuestra intención es estudiar, recuperar y difundir la industria chocolatera que desde el siglo XVIII, cuando se inició, fue en aumento hasta que en la actualidad, prácticamente ha desaparecido en Mallorca. Entendemos por tanto que contribuye a reforzar el papel de centro de investigación que tienen que ser los museos. Estos estudios se verán ampliados con la exposición de artilugios y maquinarias de elaboración del chocolate en la Secció Etnològica de Muro, que depende del Museu de Mallorca, cuando se reabra después de su rehabilitación arquitectónica y museográfica.

La difusión del gusto, la gastronomía en la Prehistoria y en la Antigüedad, son otros temas pendientes que esperamos poder llevar a cabo cuando se reabran las salas dedicadas a la Arqueología Balear, actualmente cerradas al público.

Y ya para acabar, nos gustaría unir la colección del museo, con recetarios antiguos y recrearlos con las nuevas tendencias gastronómicas que están llevando a cabo cocineras y cocineros tanto de renombre como los autores anónimos que siguen cocinado las mismas recetas desde hace siglos. Gusto por la tradición y por la innovación.

\footnotetext{
2 Se contabilizaron más de 500 personas.

3 En Onda Cero Mallorca, programa Más de Uno, Ràdio de les Illes Balears, programa Darrer Vol a Formentera y Ona Mallorca, programa Espais desde l'Antropologia y los periódicos Última Hora y Diario de Mallorca.

4 En el programa Taula Voraç de Radio Nacional, el periodista Manuel Julbe, premio Pau Llull de Gastronomía, destacó que: "En los últimos veinte años, pocos actos culturales han conseguido más entusiasmar al público. El Museo de Mallorca está en la onda. La alimentación es cultura y la gastronomía es una puerta a conocer los ricos fondos del Museo, porque conocer es proteger". En Onda Cero Mallorca, programa Más de Uno, Ràdio de les Illes Balears, programa Darrer Vol a Formentera y Ona Mallorca, programa Espais desde l'Antropologia, junto con los periódicos Última Hora y Diario de Mallorca, informaron sobre el acierto de la programación y la divulgación de temas gastronómicos en el museo.

5100 Anys de Glamur. Art i moda: un diàleg de la Collecció Antoni de Montpalau amb el Museu de Mallorca. Museu de MaIlorca del 31 d'octubre de 2019 al 28 de febrer de 2020. Palma de Mallorca. Catàleg digital.
} 


\section{Bibliografía}

ABAD ALEGRÍA, F. (2009). Líneas maestras de la gastronomía y la culinaria españolas (siglo XX). Barcelona: Trea.

ALBALA, K. (2002). Eating Right in the Renaissance. Berkeley: University of California Press.

ALBALA, K. y EDEN T. (2011). Food and Faith in Christian Culture. Berkeley: University of California Press.

ARMANIOS, F. y ERGENE, B. (2018). Halal Food: A History. Oxford: Oxford University Press.

BARCELÓ CRESPÍ, M. y ROSSELLÓ BORDOY, G. (1996). Terrissa: dades documentals per a l'estudi de la ceràmica mallorquina del segle XV. Barcelona: Canon.

BLECH, Z. Y. (2009). Kosher Food Production. Iowa: John Wiley \& Sons.

Bober, P. P. (2001). Art, Culture, and Cuisine: Ancient and Medieval Gastronomy. Chicago: Chicago University Press.

BOLÒS i MASCLANS, J. Ceràmica grisa i terrissa popular de la Catalunya medieval. Barcelona: Universitat de Barcelona.

CARTAY ARTULO, R. (1991). Historia de la alimentación del Nuevo Mundo. Caracas: Fundación Polar y Universidad de los Andes.

CHOMSKY, D. (2009). Cocina judía para celebrar la vida. Comidas de fiesta según fuentes hebreas clásicas, la Cábala y la tradición. Barcelona: Trea.

CONCA MESSINA, S. A. et. al. (2019). A History of Wine in Europe, 19th to 20th Centuries, Volume II: Markets, Trade and Regulation of Quality. London: Springer Nature.

CONTRERAS, J. (1995). "Introducción" en Contreras J. Alimentación y cultura: necesidades, gustos y costumbres. Barcelona: Universitat de Barcelona.

CONTRERAS, J., GRACIA, M. (2014). "La prevención de la obesidad en España: una lectura crítica desde la antropología" en ETNICEX, vol. 4, p. 41-61.

FLANDRIN, J. L. y MONTANARI, M (2004). Historia de la alimentación. Barcelona: Trea.

FREEDMAN, P. et al. Food. History of Taste. Berkeley: University of California Press.

GARCÍA SOLER, M. J. (2001). El arte de comer en la antigua Grecia. Madrid: Biblioteca Nueva.

GIACOSA, I. G. (1994). A Taste of Ancient Rome. Chicago: Chicago University Press.

HUICI MIRANDA A. (2016). La cocina hispano-magrebí durante la época almohade. Barcelona: Trea.

JACINTO GARCÍA, L. y TOVAR, R. (2007). Un banquete por Sefarad. Cocina y costumbres de los judíos españoles. Barcelona: Trea.

ROSSELLÓ BORDOY, G. y BALTASAR COLL T. (1997). La cerámica popular en las Islas Baleares. Palma de Mallorca: Àmbit.

LUJÁN, N. (2019). Historia de la gastronomía. Madrid: Debate. 
MCNEIL, C. L. (2009). Chocolate in Mesoamerica: A Cultural History of Cacao. Berkeley: University Press of Florida.

MONTANARI, M. (1997). La fame e l'abbondanza. Firenze: Laterza.

MONTANARI, M. (2006). La comida como cultura. Barcelona: Trea.

MONTANARI, M. (2019). Gusti del medioevo. I prodotti, la cucina, la tavola. Firenze: Laterza.

PADILLA, J. I. et al. (1998). Ceràmica medieval i postmedieval: circuits productius i seqüències culturals. Barcelona: Universitat de Barcelona.

PÉREZ SAMPER, M. A. (1998). La alimentación en la España del Siglo de Oro. Lleida: Vall d'Onsera.

PÉREZ SAMPER, M. A. (2011). Mesas y cocinas en la España del siglo XVIII. Barcelona: Trea.

PÉREZ SAMPER, M. A. (2019). Comer y beber: Una historia de la alimentación en España. Barcelona: Trea.

PUIGGRÒS i JOVÉ, J. M. (2019). La cultura de la vinya i el vi a Catalunya, de l'edat mitjana als temps actuals. Barcelona: Universitat de Barcelona.

SANTACANA MESTRE, J. (2011). Lo sagrado y lo abominable. La cocina de los pueblos prerromanos de España. Barcelona: Trea.

TOUSSAINT-SAMAT, M. (2009). History of Food. Oxford: John Wiley \& Sons.

SELLA MONTSERRAT J. (2009). Comer como un rey. Las mesas de Amadeo I de Saboya y Alfonso XII de Borbón. Barcelona: Trea. 